\title{
Childhood Testicular Mature Teratoma
}

National Cancer Institute

\section{Source}

National Cancer Institute. Childhood Testicular Mature Teratoma. NCI Thesaurus. Code C123837.

A mature teratoma that arises from the testis and occurs in children. 